\title{
A multiple cross-cultural comparison of approaches to learning
}

\author{
Mark P. Bowden ${ }^{\mathrm{a} *}$, Subhash Abhayawansa ${ }^{\mathrm{a}}$ and Gregoria Manzin ${ }^{\mathrm{b}}$ \\ ${ }^{a}$ Faculty of Business and Enterprise, Swinburne University of Technology, \\ Melbourne, Australia; ${ }^{b}$ School of Languages and Linguistics, The University of \\ Melbourne, Melbourne, Australia
}

\begin{abstract}
This study compares learning approaches of local English-speaking students and students from Asian countries studying at an Australian metropolitan university. The sample consists of students across 13 different countries. Unlike previous studies, students from Asian countries are subdivided into two categories: students from Confucian Heritage Cultures (CHC) and students from Asia-based non-Confucian Heritage Cultures (non-CHC). The rich diversity of student background enables meaningful comparison between cultural groups. There are three key findings. Firstly, $\mathrm{CHC}$ and non-CHC students are more likely to adopt a deep learning approach than local English-speaking (LES) students. Secondly, CHC students show a strong tendency to simultaneously adopt surface and deep approaches to learning. This tendency also exists with non-CHC students, albeit not as strongly as in the former group. The LES students show the least tendency to adopt this mixed approach. Thirdly, memorisation appears correlated with deep learning across all three groups. The study is exploratory in nature but, if confirmed with larger samples, points to the need for further research beyond the traditional focus on $\mathrm{CHC}$ students on the role that memorisation and culture play in learning.
\end{abstract}

Keywords: student approaches to learning; Confucian Heritage Cultures; non-Confucian Heritage Cultures based in Asia; local English-speaking

\section{Introduction}

The student cohort of Australian universities is experiencing a major shift in composition, with a large and increasing proportion of the student population coming from a non-English-speaking background. According to the data collected by Australian Education International (2011) more than 62\% of the 243,591 international students enrolled in Australian universities in 2010 came from China, India, Malaysia, Vietnam and Indonesia. The overseas student population is expected to increase further in the future (Department of Immigration and Citizenship 2011). This has put into focus

*Corresponding author. Email: mbowden@swin.edu.au 
the learning approaches and preferences of international students. There have been many studies exploring learning approaches of students from Confucian Heritage Cultures (CHC). These studies consistently recognise students from $\mathrm{CHC}$ as adopting deep learning approaches. Moreover, the literature reveals common traits among students from countries included in this category, thereby leading to the development of a theory in which culture is viewed as a major factor influencing student learning approaches (Brown et al. 2007; Cooper 2004; Donald and Jackling 2007; Leung, Ginns, and Kember 2008). However, there is a visible scarcity of studies focusing on students from other international origins, and particularly from Asian countries that are not considered CHC, such as Indonesia, India and Pakistan. Further, despite the recognition of the impact that culture exercises on learning approaches, this literature on students from Asia-based non-Confucian Heritage Cultures examines learning approaches at the country level.

The purpose of this paper is to examine learning approaches (using the Study Process Questionnaire [SPQ]) of students from a larger set of cultures (and countries). This study groups students by cultural heritage rather than by country of origin to better understand the differences and similarities between cultural groups. In this study we originally differentiate between students from $\mathrm{CHC}$ and those from other Asian countries (defined as nonCHC students). The differentiation between these two cultural groups can be motivated by two factors, namely the cultural impact played by the religious traditions of these countries as well as the influence of Western models on an educational and societal level as a consequence of the colonial experience. This second factor has been implicitly recognised as significant in the literature. For instance, Marambe, Vermunt, and Boshuizen (2012), while characterising both the Sri Lankan and the Indonesian groups in their sample, mentioned the impact that the Western model played on the national educational system. The learning approaches of these two groups are then compared to local English-speaking (LES) students.

When comparing learning approaches of $\mathrm{CHC}$ and non-CHC students studying in an overseas campus with local students of that campus, it is important to recognise the impact of the institutional learning environment on approaches to learning of overseas students (Abhayawansa and Fonseca 2010). In addition, learning approaches of students from foreign cultures may be influenced by local culture when students interact with each other in group learning situations. To this end we note that approaches to learning are neither stable traits nor fixed characteristics. Rather, they should be viewed as attempts to describe students in set learning situations (Ramsden 1987).

While acknowledging the importance of the learning environment, overseas students do bring with them learning strategies and study habits that have been shaped by their cultural and educational environments over a long history of schooling in their home country (Marambe, Vermunt, and 
Boshuizen 2012). It has been found that when exposed to a foreign learning environment, students rely heavily on those learning conceptions and strategies, that is, their learning approaches are influenced by their native culture (Duff and McKinstry 2007; Lucas 2001). Bieman and Van Mil (2008) found that the influence of learning strategies developed in their home country is so strong that Chinese students struggled to perform academically well in a Dutch university that demanded the adoption of different learning strategies.

We find that students from both $\mathrm{CHC}$ and non-CHC are more likely to adopt deep learning approaches than LES students. A cross-cultural pattern emerges whereby $\mathrm{CHC}$ students show a strong tendency to simultaneously adopt surface and deep approaches to learning. This tendency also exists with non-CHC students, albeit not as strongly as in the former group. The LES students show the least tendency to adopt this mixed approach. It is also found that non-CHC students tend to share learning characteristics with both groups, while there is little in common between CHC and LES students.

Further, memorisation is correlated with deep learning across all three cultural groups. The literature abounds with evidence (based around culture) suggesting that $\mathrm{CHC}$ students use memorisation as a path to deep learning (see for example the work of Ajisuksmo and Vermunt [1999] and Biggs [1996]). However, the role that memorisation plays as part of a deep learning approach in other cultures demands consideration. The work of Meyer and colleagues (Meyer 2000a; Meyer and Shanahan 2003) is noteworthy for its contribution in unravelling the variations in contrasting forms of memorising in a bid to understand the correlation between the deep approach to learning and memorisation. Our findings could be situated against the backdrop of the body of research on dissonant patterns of interrelations among learning conceptions, intentions, motives and processes resulting in theoretically inconsistent approaches to learning or learning styles (Entwistle, Tait, and McCune 2000; Lindblom-Ylänne and Lonka 2000; Meyer 2000b; Vermunt and Verloop 2000). Our paper adds to this understanding by analysing the intercorrelation between factors contributing to a surface approach and the student's level of deep learning. We suggest that culture, religious backgrounds and colonisation may help in contextualising this result.

The finding that deep and surface approaches strongly co-exist suggests contradictions within the model of approaches to learning. Haggis (2003) states that the lack of fit between the 'model of learning approaches' and different cultural contexts may be an indication of contradictions within the model. The results in this study suggest that memorisation cannot be simply discarded as an instrument leading to surface learning. Rather, memorisation is a key ingredient in deep learning for all cultural groups, not only $\mathrm{CHC}$ students. This study highlights the need to construct models of student learning that recognise the role of memorising in a deep approach to learning. 
To the best of our knowledge, there have been no previous studies based on a multi-country and multicultural approach comparing learning approaches of students distinguishing between $\mathrm{CHC}$ and non-CHC (Asiabased) students. The results of this study are based on a single institution and are exploratory in nature. However, the sample has sufficient representation from each cultural group to enable meaningful comparison between these groups. The study points to the need for further work with larger samples to see if, indeed, the trends indicated can be generalised. Should this be found to be the case, then research needs to move beyond the traditional focus on $\mathrm{CHC}$ students with regard to the role that memorisation and culture play in learning.

\section{Learning approaches}

Research on approaches to learning is a strongly theorised area within higher education. It offers educators a valuable means to understand the impact of student-specific attributes and learning contexts on student learning outcomes (Biggs 1979). Two approaches to learning have been identified - the surface and the deep approach. According to the surface approach, students attempt to memorise as much information as possible. In other words, they aim to reproduce information rather than elaborate a network of meaning with the purpose of establishing connections between previous knowledge and the new information (Ramsden 1979). Conversely, the deep approach occurs when students significantly engage with the content, creating internal links in their own search for meaning.

In addition to the above-mentioned approaches, Biggs (1978) and Ramsden (1979) separately identified a third - the achieving approach. Students with an achieving approach to learning are driven by the need for achievement as a form of ego-enhancement. Consequently, they work towards maximising grades for their own practical benefits (Biggs 1979; Tickle 2001). Subsequent research by Biggs (1987a, 1987b) revealed that each learning approach comprises two components - motive and strategy. Students' adoption of a particular learning strategy is determined by their own dominant learning motive. For instance, a surface strategy is supported by a surface motive. Empirical support for motive-strategy congruence within approaches to learning is confirmed in the literature (Entwistle and Tait 1990). In this paper, we use Biggs' model of surface, deep and achieving approaches. However, the focus of the paper is to understand the relationship between deep and surface approaches to learning.

Early work on student approaches to learning carried out with Western students initially deemed surface and deep approaches to be dichotomous. However, extant research suggests that the various approaches to learning are not mutually exclusive, but form a continuum (Leung, Ginns, and Kember 2008). Although students may have a predisposition towards a 
particular approach, they may adopt varying levels of each approach in any given situation depending on their own perception of the context in which learning takes place (Pandey and Zimitat 2007). Leung, Ginns, and Kember (2008) addressed this situation by identifying 'intermediate approaches', which combine memorising and understanding.

\section{Learning approaches of $\mathrm{CHC}$ and non-CHC students}

\subsection{Learners from $\mathrm{CHC}$}

In the 1980s, educators subscribed to a widespread perception that East-Asian students tend to favour rote learning and the surface approach, thus demonstrating a prevalence of low-level cognitive strategies (Ballard 1987; Samuelowicz 1987). Such a perception was then reinforced by the observation of East-Asian student behaviour in the class environment, often deemed too docile to the point of verging on passivity (Biggs 1996). However, data shows that East-Asian students are outperforming local Western students, despite their apparent adoption of rote learning techniques (Biggs 1996; Marton, Dall' Alba, and Kun 1996). This fact suggests that what has been perceived as a tendency to opt for the surface approach might, indeed, mask a less easily identifiable adoption of the deep approach to learning. While performance is not an indicator of the deep approach, CHC students' results indicate the necessity to further explore the dynamics at play in memorisation. To this end, Meyer (2000a, 166) highlighted how Dahlin and Watkins (1997) had already noted the existence of "evidence that, for some students, "memorising" as repetition is a step towards "understanding" (166). There is now significant evidence that students from CHC are at least as inclined to deep, if not deeper, learning as their Western English-speaking counterparts (Brown et al. 2007; Cooper 2004; Donald and Jackling 2007; Leung, Ginns, and Kember 2008). This is referred to as 'the paradox of the Chinese learner' in the student learning literature.

Research thus demonstrates that learning strategies based on repetition and memorisation, favoured by students from $\mathrm{CHC}$, do not equate or lead to surface learning, rather they mask a deep learning approach. Confucian philosophy offers a possible explanation for this phenomenon, in that it attributes a different meaning and function to repetition. Repetition is perceived as a necessary premise for deep understanding and production of meaning. As Tait (2010) points out, Chinese learners use memorisation as their first step towards a development of understanding. Tan (2010) also considered the difference in the learning process of Chinese-speaking students compared to English-speaking students and discussed the impact of such a difference on learning approaches. In ideogram-based languages such as Chinese and Japanese, an average of 4000 to 5000 characters (each with their own distinct meaning) may be required for functional 
daily activities - a task demanding years of repetition and memory-based learning from early childhood. Therefore, it can be argued that this requirement must have an impact on approaches to learning developed by native speakers of ideogram-based languages.

In order to unravel the 'paradox of the Chinese learner', Marton, Dall' Alba, and Kun (1996) argue that distinctions within memorisation rather than between memorisation and understanding should be investigated. Meyer (2000a) contrasts between various forms of memorisation to distinguish between the Western notion of memorising, which is akin to rote learning, and the Asian version that contributes to deep learning. The author identifies three forms of 'memorising' that are independent of one another. First is 'memorising' associated with rote learning - the act of committing to memory that which is not understood or comprehended. The two other forms of memorising differ from the first as the objective of 'memorising' is to understand or comprehend in a way that makes personal sense to the learner. These two forms are 'memorising as repetition towards understanding' ('memorising before understanding') and memorising followed by understanding ('memorising after understanding').

On the basis of a review of phenomenographic research in student learning, Meyer and Shanahan (2003) explained further variations of memorising with some being special limiting cases of the aforementioned forms. They argue that 'memorising before understanding' may or may not be performed with an intention to comprehend, and a special case of 'memorising after understanding' is 'memorising with understanding', where understanding is the organising principle for 'memorising'. Variants of memorising that are intended to result in comprehension should arguably be associated with the deep approach, while 'memorising as rehearsal' should not. Nonetheless, some research finds dissonance between forms of memorising and approaches to learning (e.g., Meyer and Shanahan 2003). Lucas and Meyer (2005) found that in a factor analysis of responses to a learning inventory designed to understand variations in approaches to learning, 'memorising as rehearsal' loaded on accumulative (surface) as well as transformative (deep) learning factors for some groups of students. Further, Lindblom-Ylänne (2003) found that a group of students scored highly on scales related to deep approaches to learning as well as memorising as rehearsal.

\subsection{Learners from non-CHC}

Research on learning approaches of students from non-CHC, including India and the Indian sub-continent, is quite scarce. This shortage stands in contrast to the growing economic significance of these student cohorts in the tertiary education sector in Australia (Australian Education International 2011), as well as other Western countries such as the USA and the UK (Organisation for Economic Co-operation and Development 2011). 
Watkins, Regmi, and Astilla (1991) compared learning approaches of 14-16-year-old Filipino and Nepalese secondary school students to those of Australia and Hong Kong-based students of similar age by using data originally reported in Watkins and Hattie's (1990) study. Although Watkins et al.'s (1991) study revealed the existence of similar learning processes in each culture, Nepalese students appeared to reach higher levels of deep approaches in comparison to students from the other three countries. Similarly, Watkins and Ismail (1994) analysed learning motives and strategies utilising a sample that included Malaysian junior high school students, Australian and Hong Kong students. In this study, Malaysian and Hong Kong students demonstrated a higher level of deep learning motivations and strategies than that measured among their Australian counterparts.

A further example is offered by Watkins and Regmi (1990), who found that Nepalese tertiary students were more inclined to adopt deep learning strategies when compared to Australian tertiary students. Interestingly, Abhayawansa and Fonseca's (2010) findings point in a different direction: in their sample, Sri Lankan students displayed lower-order conceptions of learning paired to surface learning orientation. The authors attributed these results to the Sri Lankan school education system, which encourages memorisation and a teacher-centred approach.

Finally, a study by Dahlin and Regmi (1997), focusing on a sample of Nepalese students, highlights the students' tendency to employ a deep approach to learning characterised by a mix of memorising and understanding. This study extended the intermediate approach to learning observed among $\mathrm{CHC}$ students to non-CHC students in Leung, Ginns, and Kember (2008).

\section{The survey and the sample}

The Study Process Questionnaire (SPQ) developed by Biggs (1987a, 1987b) was used to identify students' preferred learning approaches. It was complemented with several demographic questions on the students' background. The SPQ has been widely used in the education literature to investigate approaches to learning in university students across various countries, contexts and academic disciplines (see, Biggs 1987b; Watkins and Akande 1992; Watkins and Regmi 1990). The questionnaire was administered voluntarily to second- and third-year undergraduate students majoring in accounting, finance or accounting and finance in a metropolitan university in Australia. There were 273 completed questionnaires and 38 responses were disregarded because answers to key questions were left blank or because the student was not a member of one of the three groups investigated in this study - CHC, non-CHC and LES.

Table 1 highlights the demographics of the sample. The sample's demographic characteristics are broadly consistent with the characteristics of 
Table 1. Descriptive statistics.

\begin{tabular}{llcc}
\hline Demographic & Category & Frequency & $\%$ \\
\hline Gender & Male & 116 & 49.4 \\
& Female & 119 & 50.6 \\
Study mode & Full-time & 210 & 89.4 \\
& Part-time & 25 & 10.6 \\
Previous accounting studies & Studied accounting & 116 & 49.4 \\
& Not studied accounting & 1119 & 50.6 \\
Year of study & & & \\
& Second year & 134 & 57.0 \\
Student status & Third year & 101 & 43.0 \\
& & & \\
Group & Local & 134 & 57.0 \\
& International & 101 & 43.0 \\
& & & 413 \\
& LES & 67 & 26.8 \\
& CHC & 55 & 22.0 \\
\hline
\end{tabular}

the student population at the host institution. Students were grouped into the three above-mentioned categories according to their native language. The LES students are defined as students who identified themselves as local students and, through a second question, identified English as their native language. Consistent with Saravanamuthu (2008) and Watkins (1996), the category CHC included students from China, Japan, Hong Kong, Korea and Taiwan. Students from Pakistan, Vietnam, India, Indonesia, Sri Lanka, Nepal, Thailand and Cambodia were grouped under the non-CHC category. We believe that there are a sufficient number of observations in each cultural group to enable a meaningful comparison between groups.

The present study tested the construct validity of the measures for student approaches to learning using principal component factor analysis (with Varimax rotation) of the six subscales of the SPQ. The Kaiser-MeyerOklin value exceeded the recommended value of 0.6 (Kaiser 1970, 1974) and the Bartlett's Test of Sphericity (Barlett 1954) was statistically significant at better than $1 \%$. The principal component analysis produced two components with eigenvalues exceeding 1 . The rotated solution revealed that the two components yielded simple structure, with Component 1 showing strong loading from deep motive, deep strategy, achieving motive and achieving strategy subscales and Component 2 having strong loading from achieving motive, surface motive and surface strategy subscales. The factor solution explained a total of $71.43 \%$ of the common variance, with Components 1 to 2 contributing $50.98 \%$ and $20.46 \%$, respectively. The 
factor solution in this study is very similar to the one found in prior studies using the SPQ (see, Biggs 1987b; Watkins and Akande 1992; Watkins and Regmi 1990) and the Approaches to Studying Inventory (Watkins, Hattie, and Astilla 1986). It is also consistent with arguments supporting the coexistence of the achieving approach with either the surface or deep approach, depending on the specifics of the learning context (Richardson 1994; Zeegers 2002).

\section{Data analysis}

\subsection{Descriptive analysis}

The starting point for the analysis was a comparison of the strategies, motives and approaches for each of the groups. Figure 1 shows the 'mean difference' (MD) for learning motives and strategies for each group. The MD for each group is calculated as the difference between 'the mean of that group' and 'the average of the means of the four groups'. ${ }^{1}$ Panels A and B relate to surface and deep learning orientations, respectively.

An inspection of Figure 1 (Panel A) reveals that there is little difference between the three groups in the surface learning orientation, although non-CHC students display the highest level of surface strategy and motive when compared to the other two groups. Panel B shows that Asian students ( $\mathrm{CHC}$ and non-CHC together) have stronger deep learning orientations in comparison to LES students. Further, non-CHC students show a stronger tendency towards deep learning orientation when compared to CHC students.

\subsection{Approaches to learning by group}

Table 2 shows the mean of each of the three learning approaches for each group.

Two main observations emerge from Table 2. The first is that students from non-CHC reach higher levels across both categories of learning approaches when compared to the other two groups. A number of $t$-tests (assuming equal variance) were conducted to determine if the difference in learning approaches between $\mathrm{CHC}$ and non-CHC was statistically significant. For surface and deep approaches the significance for a two-tailed test equalled 0.031 and 0.177 , respectively. Therefore, a difference in the deep approach can be rejected at the $10 \%$ level. However, differences in surface approach to learning cannot be rejected.

It is also found that LES students scored lower on the deep approach compared to both Asian cultural groups at the 1\% level. However, on the level of surface learning, LES students were not significantly different from either of these groups ( $\mathrm{CHC}$ and non-CHC) even at the 5\% level. The second observation is that all students appear to show a higher surface 
Panel A. Surface learning orientation

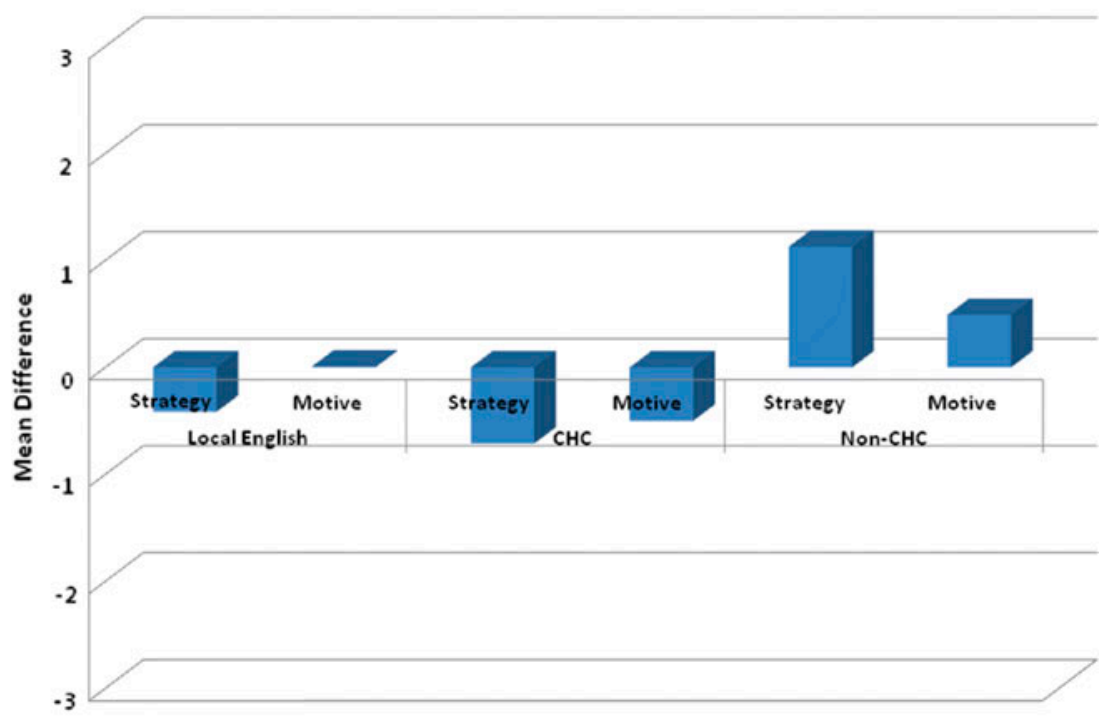

Panel B. Deep learning orientation

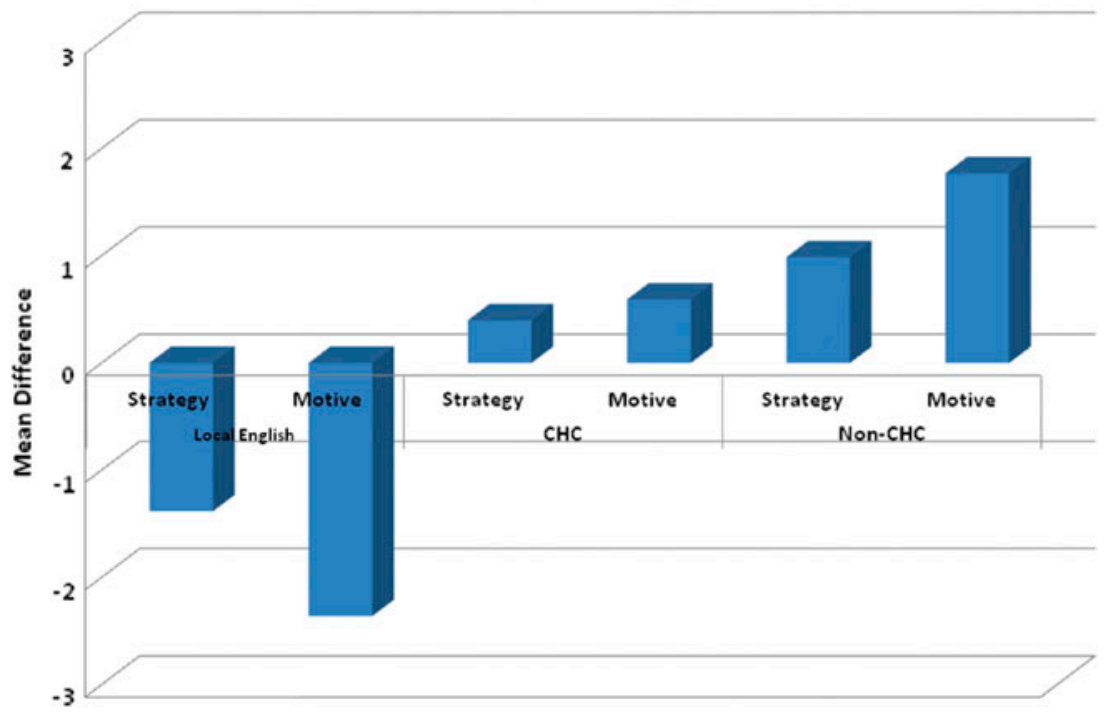

Figure 1. Comparison of learning approaches across cultural groups.

learning orientation rather than a deep learning orientation. Independent sample $t$-tests showed that the difference between surface and deep approaches was significant for all categories but the CHC group.

In order to gain a better appreciation of the impact of the cultural differences, we also conducted an ordinary least squares (OLS) regression 
Table 2. Mean scores of approaches to learning by cultural group.

\begin{tabular}{lcc}
\hline & Surface approach & Deep approach \\
\hline LES & 48.26 & 40.94 \\
CHC & 47.46 & 45.67 \\
Non-CHC & 50.29 & 47.44 \\
\hline
\end{tabular}

analysis. The control variables included gender, study mode (i.e., part- or full-time study), student status (i.e., international or local), year of study (i.e., second- or third-year students) and previous accounting study experience. The analysis was run for each of the approaches to learning and the results are presented in Table 3.

For the surface approach, none of the cultural group variables are significant in Regression 1. Therefore, while $t$-tests suggest that learners from non-CHC score higher in surface learning than learners from CHC (see Table 2), once controlling variables are taken into account, this difference becomes non-significant. Turning to Regression 2, inspection of the means reveals that the scores related to the deep approach for $\mathrm{CHC}$ and non-CHC are significantly different from those of LES students.

Table 3. OLS regression analysis.

\begin{tabular}{|c|c|c|c|c|c|c|}
\hline \multirow[b]{2}{*}{ Independent variables } & \multicolumn{3}{|c|}{ Surface } & \multicolumn{3}{|c|}{ Deep } \\
\hline & Coeff. & $\begin{array}{l}\text { Std. } \\
\text { error }\end{array}$ & Sig. & Coeff. & $\begin{array}{l}\text { Std. } \\
\text { error }\end{array}$ & Sig. \\
\hline Constant & 48.90 & 0.928 & .000 & 39.66 & 1.06 & .000 \\
\hline $\begin{array}{l}\text { International students } \\
\text { (Local students as reference) }\end{array}$ & -1.50 & 1.67 & .369 & -3.28 & 1.91 & .087 \\
\hline $\begin{array}{l}\text { Part time } \\
\text { (Full-time students as reference) }\end{array}$ & -3.75 & 1.49 & .012 & 0.64 & 1.71 & .709 \\
\hline $\begin{array}{l}\text { No previous accounting studies } \\
\text { (Previous accounting studies as } \\
\text { reference) }\end{array}$ & 0.436 & 0.89 & .625 & 2.22 & 1.02 & .031 \\
\hline $\begin{array}{l}\text { Female } \\
\text { (Male students as reference) }\end{array}$ & 2.119 & 0.92 & .022 & 0.648 & 1.05 & .538 \\
\hline $\begin{array}{l}\text { Third-year students } \\
\text { (Second-year students as } \\
\text { reference) }\end{array}$ & -2.28 & 0.91 & .012 & 0.227 & 1.03 & .826 \\
\hline $\begin{array}{l}\text { CHC } \\
\text { (LES as reference) }\end{array}$ & -0.39 & 1.83 & .83 & 7.31 & 2.10 & .001 \\
\hline $\begin{array}{l}\text { Non-CHC (Asia-based) } \\
\text { (LES as reference) }\end{array}$ & 1.934 & 1.67 & .246 & 8.79 & 1.91 & .000 \\
\hline Adjusted $\mathrm{R}^{2}(\%)$ & 6.1 & & & 27 & & \\
\hline
\end{tabular}




\subsection{Association between surface and deep approaches}

In order to further explore the relationship between deep and surface approaches, we first measured the association between surface and deep approaches for each group. The Pearson's coefficients of correlations are shown in Table 4. We then measured the inter-correlation between each of the subscales of the SPQ for each of the groups (see Table 5).

As Table 4 illustrates, surface and deep approaches for both Asian groups are highly correlated and significant to the $1 \%$ level, with $\mathrm{CHC}$ students having a strong correlation coefficient of 0.636 , which is substantially higher than that of non-CHC students.

A review of Table 5 shows that there is little relationship between surface motive/strategy and deep motive/strategy for LES students. However, for non-CHC students, surface motive and surface strategy are associated with deep motive. For CHC students, there is an even stronger relationship between surface and deep approaches to learning with all the inter-correlations between surface motive, surface strategy, deep motive and deep strategy largely significant.

The analysis was then extended by examining the inter-correlations between each of the questions that form the basis of the surface motive and strategy, and deep motive and strategy subscales. The results for each group are presented in Tables 6 and 7.

In Table 6, Q13 is correlated with both deep motive and strategy across all groups. If students can see that further education might lead to more secure or higher-paid employment, they appear more likely to opt for a deep approach to learning, while Q31 reveals that students will engage in deep learning as long as the 'end result' is deemed worthwhile, even if the student resents having to spend time studying. This result is not intuitive. It may be that the result is spurious (i.e., a type-one error) or that the question is difficult to interpret for $\mathrm{CHC}$ students.

Differences between CHC and non-CHC students emerge for Q1 and Q25. For the former group, the choice of a specific course of study as a way to securing a good job is correlated with deep learning. Further, these students also believe that lecturers should not spend time on material which will not be examined for assessment purposes. This is a result that will be addressed in the discussion and conclusion section.

Table 4. Correlations between surface and deep approaches by group.

\begin{tabular}{lcc}
\hline & Pearson's correlation & Significance \\
\hline LES & 0.104 & 0.272 \\
CHC & 0.636 & 0.000 \\
Non-CHC & 0.349 & 0.009 \\
\hline
\end{tabular}




$$
\text { 阅 }
$$


Table 6. Inter-correlation between the deep approach subscales and each of the questions in the surface motive subscale.

\begin{tabular}{|c|c|c|c|c|c|c|}
\hline & \multicolumn{2}{|c|}{ LES } & \multicolumn{2}{|c|}{$\mathrm{CHC}$} & \multicolumn{2}{|c|}{ Non-CHC } \\
\hline & $\begin{array}{l}\text { Deep } \\
\text { motive }\end{array}$ & $\begin{array}{c}\text { Deep } \\
\text { strategy }\end{array}$ & $\begin{array}{l}\text { Deep } \\
\text { motive }\end{array}$ & $\begin{array}{c}\text { Deep } \\
\text { strategy }\end{array}$ & $\begin{array}{l}\text { Deep } \\
\text { motive }\end{array}$ & $\begin{array}{c}\text { Deep } \\
\text { strategy }\end{array}$ \\
\hline Q1 & .010 & .021 & $.471^{* *}$ & $.312^{*}$ & .096 & .068 \\
\hline Q7 & .012 & .111 & $.255^{*}$ & .130 & .104 & .024 \\
\hline Q13 & $.201^{*}$ & $.287^{* *}$ & $.301^{*}$ & $.305^{*}$ & $.482^{* *}$ & $.408^{* *}$ \\
\hline Q19 & .085 & -.014 & .228 & .189 & -.001 & -.020 \\
\hline Q25 & -.026 & -.105 & $.447^{* *}$ & $.384^{* *}$ & -.252 & .019 \\
\hline Q31 & -.011 & .201 & $.520^{* *}$ & $.447^{* *}$ & $.384^{* *}$ & $.314^{*}$ \\
\hline Q37 & .165 & .117 & $.291^{*}$ & .172 & .152 & .013 \\
\hline
\end{tabular}

Notes: Q1: I chose my present courses largely with a view to securing a good job when I graduate. Q7: I am discouraged by a poor mark on a test or exam and worry about how I will do on the next assessment. Q13: Whether I like it or not, I can see that further education is for me a good way to get a well-paid or secure job. Q19: Even when I have studied hard for a test or exam, I worry that I may not be able to do well in it. Q25: Lecturers should not expect students to spend time studying material that will not be examined. Q31: I almost resent having to spend time studying further, but feel that the end results will make it all worthwhile. Q37: I attend university because I feel that I will be able to obtain a better job if I have a tertiary qualification.

significant at $5 \% ;{ }^{* *}$ significant at $1 \%$.

Table 7 reveals a strong and positive correlation between the idea of 'knowing something by heart' (Q10) and deep learning. Another important association that emerges from this analysis brings together deep learning with the need for organised and well-prepared learning materials (Q28).

Turning now to some of the differences between the groups: for $\mathrm{CHC}$ and non-CHC students there is a strong correlation between adoption of deep learning motives/strategies and accepting teaching staff members' ideas and statements, questioning them only under special circumstances (Q34). In addition, a correlation between adoption of the deep approach and relying on lecturers to point out important areas to study exists only for CHC students (Q40). Such a link is not evident for the LES group.

Finally, Q4 and Q22 also show that LES students differ from the other groups. Specifically, $\mathrm{CHC}$ and non-CHC students appear to adopt deep learning approaches despite their tendency to concentrate exclusively on topics that will be tested through assessment tasks. This response is consistent with Q25 for CHC students in Table 6. These differences are discussed in the next section.

\section{Discussion and conclusion}

A common theme in the research on the cross-cultural differences in learning approaches is that students from $\mathrm{CHC}$ display either similar or stronger 
Table 7. Intercorrelation between the deep approach subscales and each of the questions in the surface strategy subscale.

\begin{tabular}{|c|c|c|c|c|c|c|}
\hline & \multicolumn{2}{|c|}{ LES } & \multicolumn{2}{|c|}{$\mathrm{CHC}$} & \multicolumn{2}{|c|}{ Non-CHC } \\
\hline & $\begin{array}{l}\text { Deep } \\
\text { motive }\end{array}$ & $\begin{array}{c}\text { Deep } \\
\text { strategy }\end{array}$ & $\begin{array}{l}\text { Deep } \\
\text { motive }\end{array}$ & $\begin{array}{c}\text { Deep } \\
\text { strategy }\end{array}$ & $\begin{array}{l}\text { Deep } \\
\text { motive }\end{array}$ & $\begin{array}{c}\text { Deep } \\
\text { strategy }\end{array}$ \\
\hline Q4 & $-.322^{* *}$ & $-.468^{* *}$ & $.329^{* *}$ & -.005 & -.125 & -.244 \\
\hline Q10 & $.268^{* *}$ & $.220^{*}$ & $.507^{* *}$ & $.591^{* *}$ & $.339^{*}$ & $.402^{* *}$ \\
\hline Q16 & .066 & .074 & .233 & $.345^{* *}$ & .182 & .128 \\
\hline Q22 & $-.227^{*}$ & -.157 & $.251^{*}$ & $.261^{*}$ & .194 & .018 \\
\hline Q28 & $.218^{*}$ & $.263^{* *}$ & $.435^{\text {** }}$ & $346^{* *}$ & $.268^{*}$ & .260 \\
\hline Q34 & .116 & -.043 & $329^{* *}$ & $.342^{\text {** }}$ & .169 & $.463^{* *}$ \\
\hline Q40 & .085 & -.069 & $.440^{* *}$ & $.315^{* *}$ & .212 & .055 \\
\hline
\end{tabular}

Notes: Q4: I only study seriously that material covered in class or in the course outlines. Q10: I learn some things by going over them again and again until I know them by heart. Q16: I choose subjects with more factual content material rather than those that rely more on theories and ideas. Q22: I restrict my study to that specifically set in the course, as I think it is unnecessary to do anything extra. Q28: I learn best from lecturers who work from carefully prepared notes and outline major points clearly in lectures. Q34: I accept the statements and ideas of my lecturers and question them only under special circumstances. Q40: I concentrate on what lecturers say is important rather than rely on my own judgment. significant at $5 \% ;{ }^{* *}$ significant at $1 \%$.

attitude towards the adoption of the deep approach when compared to their LES counterparts. In this study, OLS regression revealed that this finding held even after controlling for gender, study mode, student status, year of study and previous accounting study experience. Hence, findings of this study confirm prior research evidence on the differences in learning approaches of $\mathrm{CHC}$ and LES students. This study also reveals that non-CHC students demonstrate a higher inclination for the adoption of the deep approach to learning in comparison to LES students (see Table 1).

Our results suggest that both $\mathrm{CHC}$ and non-CHC students have a tendency towards adopting a deep approach to learning and, more specifically, there exists an inclination towards a simultaneous mixed adoption of deep and surface approaches when compared to LES students (see Table 4). However, a closer inspection reveals that for CHC students, the subscales of deep and surface learning are correlated. For non-CHC students, surface approach sub-scales are correlated only with deep motive (see Table 5). To gain a better understanding of the underlying causes of these correlations, we calculated the inter-correlations between the scores of the individual questions that make up the surface approach and the total scores for deep motive and strategy (Tables 6 and 7). It was found that questions 10,13 and 28 are correlated with deep learning for all groups. Question 31 was correlated for $\mathrm{CHC}$ and non-CHC students but not LES students. 
Finally, Questions 1, 16, 22, 25, 34 and 40 are correlated for $\mathrm{CHC}$ students only.

Some interesting key points emerge from this analysis. Firstly, the positive correlation between 'knowing something by heart' (Q10) with deep approach reveals that all groups favour memorisation as a path to deep learning. Further, the need for organised and well-prepared learning materials (Q28) is also correlated with deep learning across all three groups. It may be that organisation and structure facilitate deep learning and that memorisation assists in the process of organising and structuring the learning material. While we share the view of Marshall and Case (2005) that the learning approaches theory continues to provide a strong framework for thinking about student learning, despite the cultural limitations outlined by Haggis (2003), we feel that the role of memorisation in learning needs more research. Considering the importance of motivation and learning (Ning and Downing 2011), one avenue of further research is the different roles that memorisation may play in learning and how this interacts with student motivation.

Two potential explanations can be offered to decipher the correlation between Q1, Q25, Q31 and deep learning for CHC students. The first is that $\mathrm{CHC}$ students, more than any other group of students identified in this survey, utilise deep learning as a means to an end. The end could be securing a job or career or be as simple as successfully completing a subject or an exam. The second potential explanation is that the relationship between the adoption of deep learning approaches and the focus on career prospects is spurious. If this is the case, there could be another third factor at work that influences both these variables. However, answering this question requires additional data. We therefore identify this area as worthy of investigation in future research projects.

It is evident from the findings that Asian ( $\mathrm{CHC}$ and non-CHC) students who adopt the deep approach to learning also acknowledge the teacher as a source of information/knowledge. Of particular concern is the causal direction of this relationship. Specifically, it remains unclear whether it is the knowledge and expertise of the teacher that inspires deep learning or, perhaps, a fundamental respect for the teacher that facilitates the learning. Another possibility is that teachers with greater familiarity with research in learning and teaching can more easily teach in ways that promote deep learning. We suspect that cultural factors could be at the root of this correlation. Asian cultures are characterised by greater power distance than Western countries (Hofstede 2001). Marambe, Vermunt, and Boshuizen (2012) argue that in cultures where there is large power distance, the power inequality between the parent-child is perpetuated by the student-teacher relationship resulting in teachers being endowed with greater authority and venerable status. Teachers are thus treated as esteemed members of the community in these cultures. Marambe, Vermunt, and Boshuizen (2012) 
explain the Sri Lankan context, which we also considered, to be equally valid for other Asian cultures investigated in this study:

Teachers are treated with utmost respect, older teachers more than younger teachers. It is commonly seen that students stand up when a teacher enters a classroom. Teachers often outline the intellectual paths to be followed. In the classroom there is a strict order where the teacher initiates the communication etc. ... What is transferred is not seen as impersonal 'truth' but as the personal wisdom of the teacher. (313)

Similar patterns of behaviour have been noted in relation to $\mathrm{CHC}$ students by Nguyen, Terlouw, and Pilot (2006). These arguments point to the notion of trust in and respect for the teacher that is facilitating the adoption of deep learning. Nonetheless, further data is required to explore this in detail.

Our final key finding is that a cross-cultural pattern emerges in the adoption of learning approaches. While the relationship between surface and deep learning is different for LES and CHC students, non-CHC students appear to occupy what could be seen as a 'middle ground position' between these two groups, with non-CHC students sharing learning characteristics with both $\mathrm{CHC}$ and LES students.

We suspect the existence of culturally based explanations for these results. At this stage we can only offer potential suggestions to contextualise these findings, thereby proposing directions for future research addressing students from non-CHC. To this end, we bring to the fore two specific considerations that might prove useful for a better understanding of the differences between $\mathrm{CHC}$ and non-CHC students' approaches to learning.

The first relates to the historical experience of foreign colonialism shared by countries listed in the non-CHC group in this study. Some scattered attempts at analysing education in the perspective of colonialism do exist, and the literature has already suggested that the theoretical framework offered by postcolonial studies would bring valuable insights if applied to research in education (Wijewardena and Yapa 1998). In their study on undergraduate education in India, Ninnes, Aitchison, and Kalos (1999) indicated that the authoritarian approach to teaching (resulting in a teachingcentred approach) can be directly connected to the reform of the educational system following India's independence from the UK. In addition, other authors highlight how processes of de-colonisation leading to the independency of former colonial territories left little space for adequate reforms of the education systems in the decolonised areas. ${ }^{2}$ The authoritarian teachercentred approach could therefore be seen as a similarity shared by $\mathrm{CHC}$ and non-CHC students, thereby providing a potential explanation of both groups' inclination towards memorisation. As the surveyed literature on CHC students evidenced, a teacher-centred educational model might implicitly encourage students to resort to memorisation. Nonetheless, this form of 
memorisation cannot be equated to rote learning, in that it only constitutes the first phase of the learning process. Rather than being an end in itself, memorisation appears to work as an instrument to move towards higher cognitive tasks.

Secondly, religious traditions should be taken into consideration as another potentially significant influence on the development of preferences for specific learning approaches. More evidently than in Western societies, religion and culture are intrinsically connected in $\mathrm{CHC}$ and non-CHC. Furthermore, the epistemological processes inferred by Asian religious traditions can provide further clues to contextualise $\mathrm{CHC}$ and non-CHC students' inclination towards memorisation. Hinduism and Buddhism, for instance, are both characterised by the absence of a univocal holy text, such as the Bible for Christianity. The transmission of cultural knowledge from one generation to the other is thus based on oral narrative processes (e.g. storytelling) rather than on the textual study and interpretation of the scriptures. With regard to Hinduism, it can be rightly argued that the ancient Vedas are the reference text for the Hindu tradition. Yet, as Graham (1987) pointed out, the 'ancient Vedic tradition represents the paradigmatic instance of scripture as spoken, recited word' (68). The emphasis on orality (which assumes memorisation) is also found in the transmission and understanding of Buddhist teachings (Veidlinger 2006). It follows that both Buddhism and Hinduism can be regarded as traditions that value memorisation as a fundamental instrument leading to understanding and self-reflection. Memorisation is therefore understood as a stepping stone towards the development of a true dialectic. As Hinduism and Buddhism are significant religions in non$\mathrm{CHC}$, future research on the determinants of learning approaches of students for this cultural group ought to take into consideration the impact of religion on the development of epistemological traditions in these cultures.

The above discussion helps in contextualising and explaining the general tendency towards the deep approach to learning displayed by $\mathrm{CHC}$ and non-CHC students, while solving the initial paradox posed by students' preference for memorisation. At this stage, the cultural explanation remains an informed guess but one worthy of further investigation. We also believe that the link between memorisation and deep learning, and the interaction between the cultural background of the student with the institutional learning environment, need further investigation. Students adopting a deep approach academically perform at a higher level and achieve greater educational gains than those adopting a surface approach (Byrne, Flood, and Willis 2002; English, Luckett, and Mladenovic 2004; Nelson, Duncan, Carke 2009; Paver and Gammie 2005; Ramburuth and Mladenovic 2004). It remains that contemporary research in the field of education identifies good teaching practices as discouraging a surface approach, while encouraging students to move towards a deep approach (Biggs 2012). This paper 
suggests that memorisation forms an important part of deep learning, and not only for CHC students.

\section{Acknowledgements}

We would like to thank Irene Tempone and Soma Pillay for their contribution to the original grant application, and our colleagues involved in the distribution and collection of the survey.

\section{Funding}

This research was funded through the 2008/09 research grant scheme of the Accounting and Finance Association of Australia and New Zealand.

\section{Notes}

1. If the means of LES, CHC and non-CHC are $\mathrm{X}_{1}, \mathrm{X}_{2}$ and $\mathrm{X}_{3}$ respectively, the mean difference for LES students becomes $\mathrm{MD}=\mathrm{X}_{1}-1 / 3$.

2. According to Bray (1994) one notable exception is Vietnam where Ho Chi Minh's liberation campaign included an extensive plan for the remodelling of the curriculum so as to reflect the social reform introduced by the political revolution.

\section{References}

Abhayawansa, S., and L. Fonseca. 2010. "Conceptions of Learning and Approaches to Learning - A Phenomenographic Study of a Group of Overseas Accounting Students from Sri Lanka." Accounting Education: An International Journal 19 (5): 527-550.

Ajisuksmo, C. R. P., and J. D. Vermunt. 1999. "Learning Styles and Self-Regulation of Learning at University: An Indonesian Study." Asia Pacific Journal of Education 19 (2): 45-59.

Australian Education International. 2011. "International Student Data for 2010." Accessed March 24, 2011. http://www.aei.gov.au/AEI/Statistics/StudentEnrolmentAndVisaStatistics/2010/Default.htm

Ballard, B. 1987. "Academic Adjustment: The Other Side of the Export Dollar." Higher Education Research and Development 6 (2): 109-119.

Barlett, M. S. 1954. "A Note on the Multiplying Factors for Various Chi Square Approximations." Journal of the Royal Statistical Society 16 (Series B): 296-298.

Biemans, H., and M. V. Mil. 2008. "Learning Styles of Chinese and Dutch Students Compared within the Context of Dutch Higher Education in Life Sciences." The Journal of Agricultural Education and Extension 14 (3): 265-278.

Biggs, J. B. 1978. "Individual and Group Differences in Study Processes." British Journal of Educational Psychology 48 (3): 266-279.

Biggs, J. B. 1979. "Individual Differences in Study Processes and the Quality of Learning Outcomes." Higher Education 8 (4): 381-394.

Biggs, J. B. 1987a. Learning Process Questionnaire Manual. Melbourne: Australian Council for Educational Research. 
Biggs, J. B. 1987b. Student Approaches to Learning and Studying. Hawthorn: Australian Council for Educational Research.

Biggs, J. B. 1996. "Approaches to Learning of Asian Students: A Multiple Paradox." In Asian Contributions to Cross-Cultural Psychology, edited by J. Pandley and D. Sinha, 180-199. New Delhi: Sage.

Biggs, J. B. 2012. "What the Student Does: Teaching for Enhanced Learning." Higher Education Research \& Development 31 (1): 39-55.

Bray, M. 1994. "Decolonisation and Education: New Paradigms for the Remnants of Empire." Compare: A Journal of Comparative and International Education 24 (1): 37-51.

Brown, M., M. Aoshima, L. Bolen, R. Chia, and T. Kohyama. 2007. "Cross-Cultural Learning Approaches in Students from the USA, Japan and Taiwan." School Psychology International 28 (5): 592-604.

Byrne, M., B. Flood, and P. Willis. 2002. "The Relationship between Learning Approaches and Learning Outcomes: A Study of Irish Accounting Students." Accounting Education: An International Journal 11 (1): 27-42.

Cooper, B. J. 2004. "The Enigma of the Chinese Learner." Accounting Education: An International Journal 13 (3): 289-310.

Dahlin, B., and M. P. Regmi. 1997. "Conceptions of Learning among Nepalese Students." Higher Education 33 (4): 471-493.

Dahlin, B., and D. Watkins. 1997. "The Role of Repetition in the Process of Memorising and Understanding: A Comparison of the Views of Western and Chinese School Students in Hong Kong." Paper presented at the 7th European Conference for Research on Learning and Instruction, Athens, Greece, August.

Department of Immigration and Citizenship. 2011. The Outlook for Net Overseas Migration - September 2011. Canberra: Australian Government.

Donald, J., and B. Jackling. 2007. "Approaches to Learning Accounting: A CrossCultural Study." Asian Review of Accounting 15 (2): 100-121.

Duff, A., and S. McKinstry. 2007. "Students" Approaches to Learning." Issues in Accounting Education 22 (2): 183-214.

English, L., P. Luckett, and R. Mladenovic. 2004. "Encouraging a Deep Approach to Learning through Curriculum Design." Accounting Education: An International Journal 13 (4): 461-488.

Entwistle, N., and H. Tait. 1990. "Approaches to Learning, Evaluations of Teaching, and Preferences for Contrasting Academic Environments." Higher Education 19 (2): 169-194.

Entwistle, N., H. Tait, and V. McCune. 2000. "Patterns of Response to an Approaches to Studying Inventory across Contrasting Groups and Contexts." European Journal of Psychology of Education 15 (1): 33-48.

Graham, W. A. 1987. Beyond the Written Word: Oral Aspects of Scripture in the History of Religion. Cambridge: Cambridge University Press.

Haggis, T. 2003. "Constructing Images of Ourselves? A Critical Investigation into 'Approaches to Learning' Research in Higher Education." British Educational Research Journal 29 (1): 89-104.

Hofstede, G. 2001. Culture's Consequences: Comparing Values, Behaviors, Institutions, and Organizations across Nations. 2nd ed. Thousand Oaks, CA: Sage.

Kaiser, H. 1970. "A Second Generation Little Jiffy." Psychometrika 35 (4): 401-415.

Kaiser, H. 1974. “An Index of Factorial Simplicity.” Psychometrika 39 (1): 31-36. 
Leung, D. Y. P., P. Ginns, and D. Kember. 2008. "Examining the Cultural Specificity of Approaches to Learning in Universities in Hong Kong and Sydney." Journal of Cross-Cultural Psychology 39 (3): 251-266.

Lindblom-Ylänne, S. 2003. "Broadening an Understanding of the Phenomenon of Dissonance." Studies in Higher Education 28 (1): 63-77.

Lindblorn-Ylänne, S., and K. Lonka. 2000. "Dissonant Study Orchestrations of High-Achieving University Students." European Journal of Psychology of Education 15 (1): 19-32.

Lucas, U. 2001. "Deep and Surface Approaches to Learning within Introductory Accounting: A Phenomenographic Study." Accounting Education: An International Journal 10 (2): 161-184.

Lucas, U., and J. H. F. Meyer. 2005. "“Towards a Mapping of the Student World': The Identification of Variation in Students' Conceptions of, and Motivations to Learn, Introductory Accounting." The British Accounting Review 37 (2): 177-204.

Marambe, K. N., J. D. Vermunt, and H. P. A. Boshuizen. 2012. "A Cross-Cultural Comparison of Student Learning Patterns in Higher Education." Higher Education 64 (3): 299-316.

Marshall, D., and J. Case. 2005. "Approaches to Learning Research in Higher Education: A Response to Haggis." British Educational Research Journal 31 (2): 257-267.

Marton, F., G. Dall' Alba, and T. L. Kun. 1996. "Memorising and Understanding: The Keys to the Paradox?" In The Chinese Learner: Cultural, Psychological, and Contextual Influences, edited by D. Watkins and J. B. Biggs, 69-84. Hong Kong: Comparative Education Research Centre and The Australian Council for Edcational Research.

Meyer, J. H. F. 2000a. "Variation in Contrasting Forms of 'Memorising' and Associated Observables." British Journal of Educational Psychology 70 (2): 163-176.

Meyer, J. H. F. 2000b. "The Modelling of 'Dissonant' Study Orchestration in Higher Education.” European Journal of Psychology of Education 15 (1): 5-18.

Meyer, J. H. F., and M. P. Shanahan. 2003. "Dissonant Forms of 'Memorising' and 'Repetition'." Studies in Higher Education 28 (1): 5-20.

Nelson, K. J., M. E. Duncan, and J. A. Carke. 2009. "Student Success: The Identification and Support of First Year University Students at Risk of Attrition." Studies in Learning, Evaluation, Innovation and Development 6 (1): 1-15.

Nguyen, P.-M., C. Terlouw, and A. Pilot. 2006. "Culturally Appropriate Pedagogy: The Case of Group Learning in a Confucian Heritage Culture Context." Intercultural Education 17 (1): 1-19.

Ning, H. K., and K. Downing. 2011. "Influence of Student Learning Experience on Academic Performance: The Mediator and Moderator Effects of Self-Regulation and Motivation." British Educational Research Journal 38 (2): 219-237.

Ninnes, P., C. Aitchison, and S. Kalos. 1999. "Challenges to Stereotypes of International Students' Prior Educational Experience: Undergraduate Education in India." Higher Education Research and Development 18 (3): 323-342.

Organisation for Economic Co-operation and Development. 2011. "OECD. StatExtracts - Foreign / International Students Enrolled." Accessed March 21, 2011. http://stats.oecd.org/Index.aspx?DatasetCode=RFOREIGN

Pandey, P., and C. Zimitat. 2007. "Medical Students' Learning of Anatomy: Memorisation, Understanding and Visualisation." Medical Education 41 (1): 7-14. 
Paver, B., and E. Gammie. 2005. "Constructed Gender, Approach to Learning and Academic Performance." Accounting Education: An International Journal 14 (4): 427-444.

Ramburuth, P., and R. Mladenovic. 2004. "Exploring the Relationship between Students' Orientations to Learning, the Structure of Students' Learning Outcomes and Subsequent Academic Performance." Accounting Education: An International Journal 13 (4): 507-527.

Ramsden, P. 1979. "Student Learning and Perceptions of the Academic Environment." Higher Education 8 (4): 411-427.

Ramsden, P. 1987. "Improving Teaching and Learning in Higher Education: The Case for a Relational Perspective." Studies in Higher Education 12 (3): 275286.

Richardson, J. T. E. 1994. "Cultural Specificity of Approaches to Studying in Higher Education: A Literature Survey." Higher Education 27 (4): 449-468.

Samuelowicz, K. 1987. "Learning Problems of Overseas Students: Two Sides of a Story." Higher Education Research and Development 6 (2): 121-133.

Saravanamuthu, K. 2008. "Reflecting on the Biggs-Watkins Theory of the Chinese Learner." Critical Perspectives on Accounting 19 (2): 138-180.

Tait, C. 2010. "Chinese Students' Perceptions of the Effects of Western University Examination Formats on Their Learning." Higher Education Quarterly 64 (3): 261-275.

Tan, P. L. 2010. "Towards a Culturally Sensitive and Deeper Understanding of 'Rote Learning' and Memorization of Adult Learners." Journal of Studies in International Education 15 (2): 124-145.

Tickle, S. 2001. "What Have We Learnt about Student Learning?: A Review of the Research on Study Approach and Style." Kybernetes 30 (7/8): 955-969.

Veidlinger, D. M. H. 2006. Spreading the Dhamma: Writing, Orality, and Textual Transmission in Buddhist Northern Thailand. Honolulu: University of Hawaii Press.

Vermunt, J. D., and N. Verloop. 2000. "Dissonance in Students' Regulation of Learning Processes." European Journal of Psychology of Education 15 (1): 75-89.

Watkins, D. 1996. "Learning Theories and Approaches to Research: A Cross-Cultural Perspective." In The Chinese Learner: Cultural, Psychological, and Contextual Influences, edited by D. Watkins and J. B. Biggs, 3-24. Hong Kong: Comparative Education Research Centre and The Australian Council for Educational Research.

Watkins, D., and A. Akande. 1992. "Assessing the Approaches to Learning of Nigerian Students." Assessment \& Evaluation in Higher Education 17 (1): $11-20$.

Watkins, D., and J. Hattie. 1990. "Individual and Contextual Differences in the Approaches to Learning of Australian Secondary School Students." Educational Psychology 10 (4): 333-342.

Watkins, D., J. Hattie, and E. Astilla. 1986. "Approaches to Studying by Filipino Subjects: A Longitudinal Investigation." British Journal of Educational Psychology 56 (3): 357-362.

Watkins, D., and M. Ismail. 1994. "Is the Asian Learner a Rote Learner? A Malaysian Perspective." Contemporary Educational Psychology 19 (4): 483-488.

Watkins, D., and M. Regmi. 1990. "An Investigation of the Approach to Learning of Nepalese Tertiary Students." Higher Education 20 (4): 459-469. 
Watkins, D., M. Regmi, and E. Astilla. 1991. "The-Asian-Learner-as-a-Rote-Learner Stereotype: Myth or Reality?" Educational Psychology 11 (1): 21-34.

Wijewardena, H., and S. Yapa. 1998. "Colonialism and Accounting Education in Developing Countries: The Experiences of Singapore and Sri Lanka." The International Journal of Accounting 33 (2): 269-281.

Zeegers, P. 2002. "A Revision of the Biggs' Study Process Questionnaire (R-SPQ).” Higher Education Research and Development 21 (1): 73-92. 


\section{University Library}

\section{- M M I N E R VA A gateway to Melbourne's research publications}

Minerva Access is the Institutional Repository of The University of Melbourne

Author/s:

Bowden, MP;Abhayawansa, S;Manzin, G

Title:

A multiple cross-cultural comparison of approaches to learning

Date:

2015

Citation:

Bowden, M. P., Abhayawansa, S. \& Manzin, G. (2015). A multiple cross-cultural comparison of approaches to learning. Compare, 45 (2), pp.272-294. https:// doi.org/10.1080/03057925.2013.841465.

Persistent Link:

http://hdl.handle.net/11343/112623 